\title{
$\beta$-elemene enhances both radiosensitivity and chemosensitivity of glioblastoma cells through the inhibition of the ATM signaling pathway
}

\author{
SIWEI LIU ${ }^{1}$, LEI ZHOU ${ }^{1}$, YONGSHUN ZHAO ${ }^{2 *}$ and YUHUI YUAN ${ }^{1 *}$ \\ ${ }^{1}$ Institute of Cancer Stem Cell, Dalian Medical University Cancer Center; The First Affiliated Hospital, \\ Dalian Medical University Cancer Center; ${ }^{2}$ Department of Neurosurgery, The First Affiliated Hospital, \\ Dalian Medical University, Dalian, Liaoning, P.R. China
}

Received March 13, 2015; Accepted May 8, 2015

DOI: $10.3892 /$ or.2015.4050

\begin{abstract}
Glioblastoma multiforme (GBM), a tumor associated with poor prognosis, is known to be resistant to radiotherapy and alkylating agents such as temozolomide (TMZ). $\beta$-elemene, a monomer found in Chinese traditional herbs extracted from Curcuma wenyujin, is currently being used as an antitumor drug for different types of tumors including GBM. In the present study, we investigated the roles of $\beta$-elemene in the radiosensitivity and chemosensitivity of GBM cells. Human GBM cell lines U87-MG, T98G, U251, LN229 and rat C6 cells were treated with $\beta$-elemene combined with radiation or TMZ. We used MTT and colony forming assays to evaluate the proliferation and survival of the cells, and the comet assay to observe DNA damage. Expression of proteins was analyzed by immunoblotting. In the present study, we found that $\beta$-elemene inhibited the proliferation and survival of different GBM cell lines when combined with radiotherapy or TMZ via inhibition of DNA damage repair. Treatment of GBM cells with $\beta$-elemene decreased the phosphorylation of ataxia telangiectasia mutated (ATM), AKT and ERK following radiotherapy or chemotherapy. These results revealed that $\beta$-elemene could significantly increase the radiosensitivity and chemosensitivity of GBM. $\beta$-elemene may be
\end{abstract}

Correspondence to: Dr Yuhui Yuan, Institute of Cancer Stem Cell, Dalian Medical University Cancer Center, The First Affiliated Hospital, No. 9 West Segment of South Lvshun Road, Dalian, Liaoning 116044, P.R. China

E-mail: yuhuiyuan@hotmail.com; yuhuiyuan@dlmedu.edu.cn

Dr Yongshun Zhao, Department of Neurosurgery, The First Affiliated Hospital of Dalian Medical University, 222 Zhong Shan Road, Dalian, Liaoning 116011, P.R. China

E-mail: zhaoyongshun_2005@aliyun.com

${ }^{*}$ Contributed equally

Key words: $\beta$-elemene, glioblastoma multiforme, radiotherapy, temozolomide, DNA damage used as a potential drug in combination with the radiotherapy and chemotherapy of GBM.

\section{Introduction}

Glioblastoma multiforme (GBM) is the most frequently occurring and the most aggressive malignant type of primary brain tumor in the central nervous system (CNS). GBM accounts for $15.6 \%$ of all primary brain tumors and $45.2 \%$ of primary malignant brain tumors. More than 10,000 new patients are diagnosed every year in the United States (1-4). Current standard therapy for GBM includes surgery of maximal safe resection followed by radiotherapy in combination with temozolomide (TMZ) for newly diagnosed GBM $(2,3)$. However, the relative survival estimates for GBM are very poor; less than $5 \%$ of patients survive 5 years post diagnosis (4). The reasons for the reduced survival include the early invasion of GBM into the central nervous system, making a surgical cure nearly impossible, and also the resistance to radiotherapy and TMZ (5).

Radiation induces a variety of DNA damage, including oxidized base damage, abasic sites, single-stand breaks (SSBs) and double-stand breaks (DSBs). TMZ as the first-line drug to treat GBM exerts its effects mainly via the mutagenic product $O^{6}$-methylguanine, a cytotoxic DNA lesion (6). TMZ can disrupt gene transcription and induce DSBs as well (7). It has been known that the activity of DNA repair processes, particularly DSB repair after radiotherapy and chemotherapy can regulate the response of tumor cells to treatment (8). The DSBs trigger the DNA damage response (DDR) mediated by ATM and ATR (the ATM and Rad3-related) protein kinases. ATM kinase, a member of the phosphatidylinositol 3-kinase (PI3K)-like kinase family, is activated by DSBs and then activates more than 700 proteins involved in cell cycle checkpoints, DNA repair and modulation of chromatin structure. ATM-dependent $\mathrm{H} 2 \mathrm{AX}$ phosphorylation is one of the earliest signs of DNA damage and is necessary for efficient DSB repair (9).

Except for ATM and ATR, other signaling transduction pathways such as PI3K-AKT, nuclear factor- $\kappa \mathrm{B}(\mathrm{NF}-\kappa \mathrm{B}), \mathrm{ERK}$ and transforming growth factor- $\beta$ (TGF $\beta$ ) pathways can also 
mediate radioresistance and chemoresistance by decreasing apoptosis or increasing DNA damage repair. In addition, $\sim 40 \%$ of patients with GBM have an amplified EGFR gene which results in constitutive activation of AKT and ERK (10). AKT and ERK signaling pathways play vital roles in regulating many fundamental cellular processes and they are associated with resistance to treatment in GBM cells $(11,12)$.

$\beta$-elemene, a Chinese antitumor medicine extracted from the plant Curcuma wenyujin, has been isolated as a monomeric drug and has a broad-spectrum antitumor effect in various tumor cells, such as lung (13), breast carcinoma (14), leukemia (15), ovarian cancer (16) and GBM (17). $\beta$-elemene can reverse the resistance to other drugs such as cisplatin (13). $\beta$-elemene with low toxicity has been well accepted by patients and is currently being used in clinical therapy for tumors, cancerous hydrothorax and ascites via intravenous injection, cavity or peritoneal perfusion in China.

In the present study, we investigated the roles of $\beta$-elemene in the radiosensitivity and chemosensitivity of GBM cells. We found that $\beta$-elemene significantly inhibited the repair of DNA damage of GBM cells combined with radiation or TMZ via interfering with the ATM, AKT and ERK signaling pathways.

\section{Materials and methods}

Cell lines and cell culture. The glioblastoma cell lines U87-MG, U251, T98G and LN229 from the human and C6 from the rat were used in the experiments. The GBM cells were obtained from the American Type Culture Collection (ATCC; Manassas, VA, USA). Cells were cultured in Dulbecco's modified Eagle's medium (DMEM; Gibco, Carlsbad, CA, USA) supplemented with $10 \%$ fetal bovine serum (FBS; Gibco), $100 \mathrm{IU} / \mathrm{ml}$ penicillin and $100 \mu \mathrm{g} / \mathrm{ml}$ streptomycin, and grown at $37^{\circ} \mathrm{C}$ in a humidified atmosphere with $5 \% \mathrm{CO}_{2}$.

Radiation with X-rays was performed using X-320ix (Precision X-Ray, Inc., North Branford, CO, USA) at a dose rate of $3.38 \mathrm{~Gy} / \mathrm{min}$. The cells were treated at room temperature $\left(25-26^{\circ} \mathrm{C}\right)$. The doses used were as follows: 2,4 and $6 \mathrm{~Gy}$ for colony forming, 4 Gy for comet assay and $10 \mathrm{~Gy}$ for immunoblotting.

Reagents. $\beta$-elemene which was obtained from the National Institutes for Food and Drug Control (NIFDC; Beijing, China) was dissolved in dimethyl sulfoxide (DMSO; SigmaAldrich, St. Louis, MO, USA) at $20 \mathrm{mg} / \mathrm{ml}$ as a stock solution. Temozolomide (Sigma-Aldrich) was dissolved in DMSO at $100 \mathrm{mM}$ as a stock solution. The stock solutions were diluted immediately before each experiment. For precise assays, DMSO was added to a control sample at the same concentration as the treated samples.

Cell proliferation assay. Cell viability was detected by methylthiazolyl tetrazolium (MTT) assay. The cells were cultured in a 96-well plate at a concentration of 5,000 cells/100 $\mu 1 /$ well. After incubation for $24 \mathrm{~h}$, the cells were treated with the indicated concentrations of different drugs for $48 \mathrm{~h}$. Then $10 \mu \mathrm{l}$ of $0.5 \mathrm{mg} / \mathrm{ml}$ MTT (Sigma-Aldrich) was added to each well, and the mixture was incubated at $37^{\circ} \mathrm{C}$ for $4 \mathrm{~h}$. The culture medium was replaced with $150 \mu 1 \mathrm{DMSO}$ to dissolve the formazan crystals. The absorbance of each well was determined at $490 \mathrm{~nm}$ by a plate reader (Perkin-Elmer, Waltham, MA, USA). Three replicate wells were designed for each sample.

Drug synergy was determined by combination index (CI) from the MTT assay data. The ratio CI was calculated as follows: $\mathrm{CI}=$ survival (combination)/survival (ELE) x survival (TMZ). If CI was $<0.8$, the combination was considered synergistic, if it was between 0.8 and 1.2 , the combination was considered additive, and if $\mathrm{CI}$ was $>1.2$ the combination was considered antagonistic (18).

Colony forming assay. The effects of elemene combined with radiation or TMZ on GBM cell survival were assessed by colony forming assay. For radiation, the cells were incubated with or without elemene $(40 \mu \mathrm{g} / \mathrm{ml})$ for $24 \mathrm{~h}$, and then exposed to X-rays at doses of 0, 2, 4 and $6 \mathrm{~Gy}$. After irradiation, the cells were trypsinized and seeded in a 6-well plate at the indicated numbers with fresh medium. For TMZ treatment, the cells were seeded in a 6-well plate at 500 cells/well for $24 \mathrm{~h}$, and then treated with the indicated concentrations of drugs for $48 \mathrm{~h}$; the medium was replaced with fresh medium and cultured for 14-20 days. After 14-20 days, colonies of $>50$ cells were scored as survivors. Three replicate dishes were used for each treatment.

Comet assay. After the indicated treatment, GBM cells were trypsinized and washed with ice-cold PBS. Next, the cells $\left(1.5 \times 10^{4} / 10 \mu \mathrm{l}\right)$ were embedded in $120 \mu \mathrm{l}$ of low-melting point agarose $\left(0.5 \%\right.$ in PBS at $\left.37^{\circ} \mathrm{C}\right)$ onto an agarose-coated $(1.5 \%$ in PBS) slide. Then the slides were submersed for at least $1 \mathrm{~h}$ in pre-cooled lysis buffer $(2.5 \mathrm{M} \mathrm{NaCl}, 100 \mathrm{mM}$ EDTA, $10 \mathrm{mM}$ Tris-HCl, pH 7.5) with $1 \%$ Triton X-100 and $10 \%$ DMSO. The slides were denatured for $20 \mathrm{~min}$ at $4^{\circ} \mathrm{C}$ in pre-cooled electrophoresis buffer ( $300 \mathrm{mM} \mathrm{NaOH}, 1 \mathrm{mM}$ EDTA) to allow unwinding of the DNA and run at $25 \mathrm{~V}, 300 \mathrm{~mA}$ for $20 \mathrm{~min}$ at $4^{\circ} \mathrm{C}$. The slides were coated with drops of neutralization buffer (0.4 M Tris-HCl, pH 7.5), and allowed to sit for $5 \mathrm{~min}$ for three times. The dried slides were stained with ethidium bromide $(2 \mu \mathrm{g} / \mathrm{ml})$ and images were captured using a Leica microscope. Comet Assay Software Project (CASP) was used to record the percentage of DNA in the tail for each cell. The assay was completed three separate times evaluating 50 cells/experiment.

Immunoblotting. Cells harvested after radiation and drug treatments were lysed on ice in RIPA buffer with PMSF. The buffer included $25 \mathrm{mM}$ Tris- $\mathrm{HCl}(\mathrm{pH} 7.6), 150 \mathrm{mM} \mathrm{NaCl}$, $1 \%$ Triton X-100, $1 \%$ sodium deoxycholate and $0.1 \%$ SDS. Protein concentrations were determined using the BCA protein assay kit (Thermo Fisher Scientific, Waltham, MA, USA). Samples that included the same amounts of protein were boiled for $5 \mathrm{~min}$ in Laemmli's buffer and separated by 8-12\% SDS-PAGE, followed by electroblotting on polyvinylidene fluoride membranes. The blots were incubated with the following antibodies under conditions recommended by the manufacturers. The primary antibodies against p-ERK, ERK, p-AKT, AKT, $\gamma$ H2AX, p-ATM and GAPDH (Cell Signaling Technology, Beverly, MA, USA) were used. Horseradish peroxidase-conjugated anti-mouse or anti-rabbit (Cell Signaling Technology) was used as the secondary antibodies. Singles were detected using ChemiDoc ${ }^{\mathrm{TM}}$ XRS+ Imaging System (Bio-Rad Laboratories, Hercules, CA, USA). 

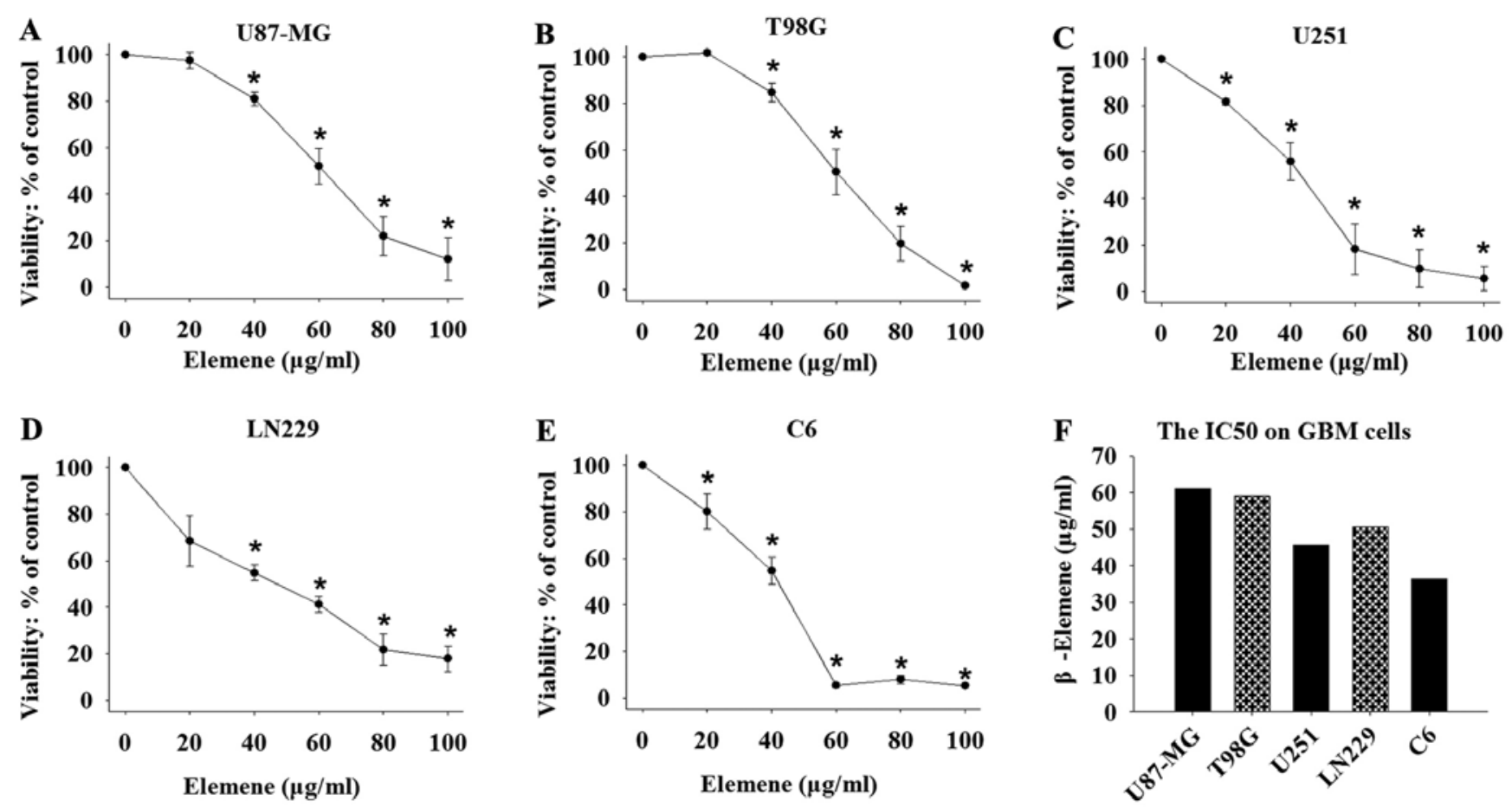

Figure 1. $\beta$-elemene inhibits the proliferation of GBM cells. Human GBM U87-MG, T98G, U251, LN229 cells and rat GBM C6 cells were seeded in 96-well plates at $5 \times 10^{3} /$ well and treated with different concentrations of $\beta$-elemene $(0,20,40,60,80$ and $100 \mu \mathrm{g} / \mathrm{ml})$ for $24 \mathrm{~h}$. (A-E) The ability of $\beta$-elemene to inhibit cell proliferation was determined by MTT assay as described in Materials and methods. The results are expressed as the mean \pm SEM of at least three independent experiments. $(\mathrm{F}) \mathrm{The}_{\mathrm{IC}} \mathrm{I}_{50}$ of the different cell lines was defined as the concentration of $\beta$-elemene needed to achieve a half-maximal inhibitory effect. ${ }^{*} \mathrm{P}<0.05$ vs. the untreated control.

\section{Results}

$\beta$-elemene inhibits the proliferation of GBM cells and enhances the radiosensitivity in different cell lines. We used MTT assay to evaluate the effects of $\beta$-elemene on the proliferation of GBM cells. The human GBM cell lines U87-MG, T98G, U251, LN229 and the rat GBM cell line C6 were used in the examination. Significant inhibition of cell proliferation was observed in each cell line following treatment with different concentrations of $\beta$-elemene at $0,20,40,60,80$ and $100 \mu \mathrm{g} / \mathrm{ml}$ for $24 \mathrm{~h}$ (Fig. 1A-E). Cell viability was calculated as a percentage of the control, and the median inhibitory concentration $\left(\mathrm{IC}_{50}\right)$ was calculated from the growth inhibition curves fitted to the data. The results showed that $\beta$-elemene caused a dose-dependent inhibition with a half-maximal inhibitory effect on GBM cell growth at $61.02 \mu \mathrm{g} / \mathrm{ml}$ for U87-MG, $59 \mu \mathrm{g} /$ $\mathrm{ml}$ for T98G, $55.66 \mu \mathrm{g} / \mathrm{ml}$ for U251, $55.95 \mu \mathrm{g} / \mathrm{ml}$ for LN229 and $36.4 \mu \mathrm{g} / \mathrm{ml}$ for C6 cells (Fig. 1F).

Then the human GBM cell lines U87-MG, T98G and U251 were used to study the effects of $\beta$-elemene on radiotherapy, and the surviving fractions (SFs) of the colony formation assays are shown in Fig. 2A-C. The cells were pretreated with $\beta$-elemene at $40 \mu \mathrm{g} / \mathrm{ml}$ for $24 \mathrm{~h}$, exposed to radiation at 0,2 , 4 and $6 \mathrm{~Gy}$, and then the cells were trypsinized and seeded in a 6-well plate and cultured for 14-20 days. The curves of the SFs were fitted by the multi-target single-hit model. For each cell line, radiosensitivity was significantly increased after cells were pretreated with $\beta$-elemene. Fig. $2 \mathrm{D}$ shows the representative images of the colony formation after treatment with radiation at $4 \mathrm{~Gy}$ alone or in combination with $\beta$-elemene.
Table I. Survival fractions at 2 Gy (SF2), quasi-threshold dose (Dq) and doses for $37 \%$ survival (D37).

\begin{tabular}{lccc}
\hline Cell lines & Control & ELE & P-value \\
\hline & \multicolumn{2}{c}{ SF2 } \\
\cline { 2 - 3 } U87-MG & $0.84 \pm 0.009$ & $0.66 \pm 0.051$ & $0.026^{\mathrm{a}}$ \\
T98G & $0.89 \pm 0.017$ & $0.67 \pm 0.010$ & $<0.01^{\mathrm{a}}$ \\
U251 & $0.83 \pm 0.041$ & $0.65 \pm 0.019$ & $0.019^{\mathrm{a}}$ \\
& \multicolumn{2}{c}{ Dq } & \\
\cline { 2 - 3 } & Control & ELE & P-value \\
U87-MG & $2.55 \pm 0.023$ & $1.95 \pm 0.164$ & $0.022^{\mathrm{a}}$ \\
T98G & $2.94 \pm 0.068$ & $1.97 \pm 0.051$ & $<0.01^{\mathrm{a}}$ \\
U251 & $2.60 \pm 0.226$ & $1.67 \pm 0.131$ & $0.024^{\mathrm{a}}$ \\
& \multicolumn{2}{c}{ D37 } & \\
\cline { 2 - 3 } & Control & ELE & DER \\
U87-MG & $3.44 \pm 0.100$ & $2.84 \pm 0.221$ & $1.21 \pm 0.063$ \\
T98G & $4.26 \pm 0.849$ & $3.09 \pm 0.104$ & $1.38 \pm 0.315$ \\
U251 & $3.98 \pm 0.409$ & $3.41 \pm 0.192$ & $1.17 \pm 0.101$ \\
\hline
\end{tabular}

Control, $\beta$-elemene(-); ELE, pretreated with $40 \mu \mathrm{g} / \mathrm{ml} \beta$-elemene for 24 h. Date values: mean \pm SEM for SF2 and Dq, mean $\pm 95 \%$ CI for D37. ${ }^{\mathrm{P}}<0.05$ group treated with $\beta$-elemene vs. untreated group.

In addition, we analyzed the difference between the groups treated with and without $\beta$-elemene following radiotherapy by 
A

U87-MG

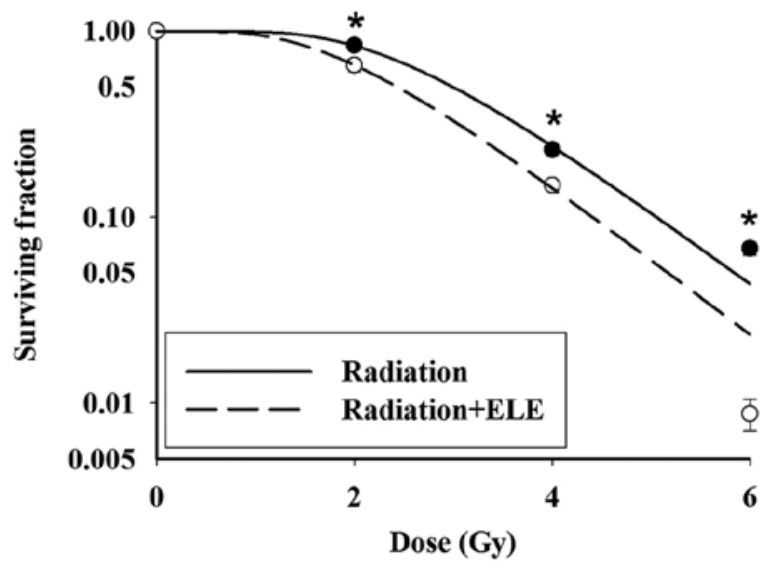

C

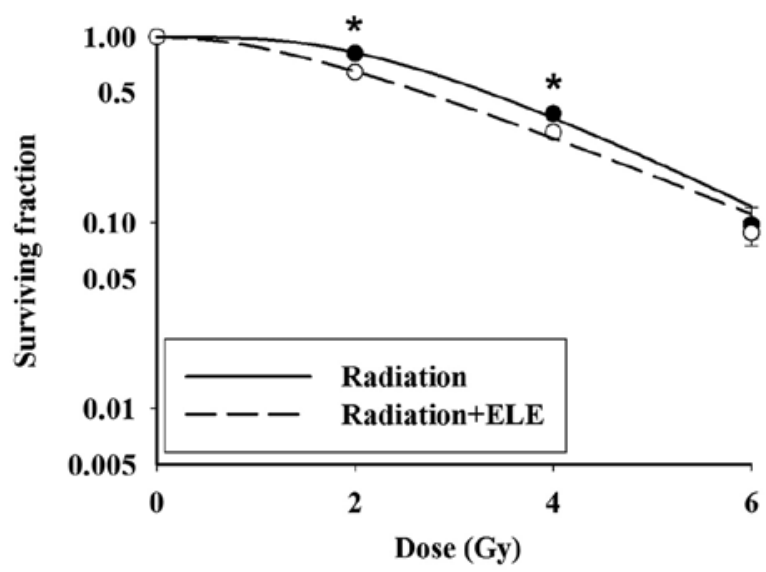

B

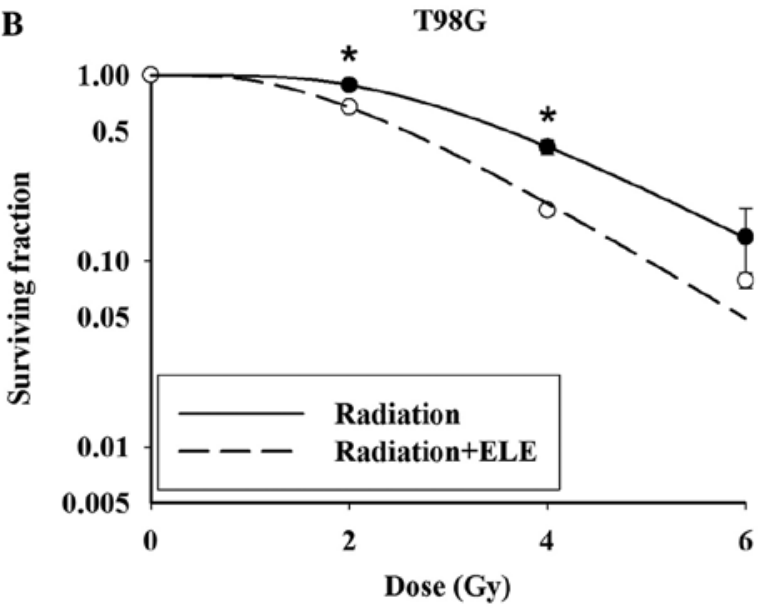

D

U87-MG

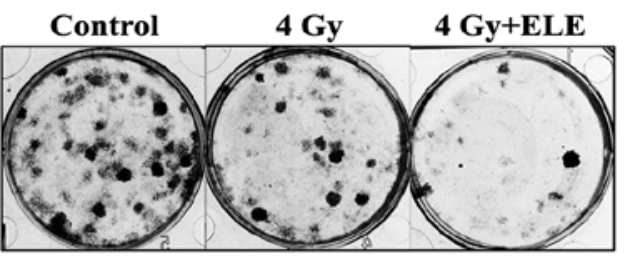

T98G

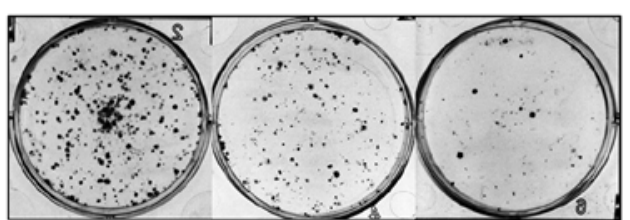

U251

Figure 2. $\beta$-elemene enhances the radiosensitivity of GBM cells. Human GBM U87-MG, T98G, U251 cells were pretreated without or with $\beta$-elemene $(40 \mu \mathrm{g} / \mathrm{ml})$ for $24 \mathrm{~h}$, and exposed to different doses of radiation at $0,2,4$ and $6 \mathrm{~Gy}$. Then the cells were seeded in a 6-well plate as 250,250,500 and 1,000/ well corresponding to $0,2,4$ and 6 Gy (A-C) or 500/well (D). (A-C) The surviving fraction curves were fitted using the multi-target single-hit model. (D) The colony formation assay was carried out as described in Materials and methods. The results are expressed as the mean \pm SEM of at least three independent experiments. ${ }^{*} \mathrm{P}<0.05$, group treated with $\beta$-elemene vs. untreated group.

calculating the SFs at 2 Gy (SF2), quasi-threshold dose (Dq) and doses of radiation for $37 \%$ survival (D37) (Table I). The data showed that $\beta$-elemene was more effective in the T98G cells with a DER of $1.38 \pm 0.315$. Taking all the factors into consideration, $\beta$-elemene significantly radiosensitized the GBM cells.

$\beta$-elemene enhances the radiation-induced DNA damage of GBM cells. We used comet assay to examine the effects of $\beta$-elemene combined with radiation on the DNA damage in GBM cells. The tail intensity (percent DNA in the tail) in the comet assay is a marker for the degree of DNA damage. The human GBM cell lines U87-MG and T98G were used in the examination. Cells were pretreated with $\beta$-elemene $(40 \mu \mathrm{g} / \mathrm{ml})$ for $24 \mathrm{~h}$, exposed to radiation at $4 \mathrm{~Gy}$ and were collected immediately or after 4 and $24 \mathrm{~h}$ to study the repair of DNA damage. We found that the DNA damage of the GBM cells was almost repaired at $24 \mathrm{~h}$ after radiation, while the cells pretreated with $\beta$-elemene still had obvious DNA damage at the same timepoint (Fig. 3). The results showed that $\beta$-elemene inhibited the repair of the DNA damage caused by radiation.

$\beta$-elemene inhibits the phosphorylation of ATM, H2AX, AKT and ERK signaling pathways to reduce the repair of DNA damage after radiation in GBM cells. To understand the mechanism of the radiosensitivity caused by $\beta$-elemene in GBM, human GBM cell lines U87-MG, T98G and U251 were pretreated with $\beta$-elemene at 20 and $40 \mu \mathrm{g} / \mathrm{ml}$ for $24 \mathrm{~h}$, exposed to radiation at $10 \mathrm{~Gy}$ and collected for immunoblotting after $5 \mathrm{~min}$. Phosphorylated ATM and $\gamma \mathrm{H} 2 \mathrm{AX}$ levels are shown in Fig. 4A-C. Furthermore, we used U87-MG cells to examine the activation of AKT and ERK following the indicated treatments. The levels of total and phosphorylated AKT and ERK were analyzed and are shown in Fig. 4D. The results showed that $\beta$-elemene significantly inhibited the radiation-induced phosphorylation of ATM, AKT and ERK. 
$\mathbf{A}$
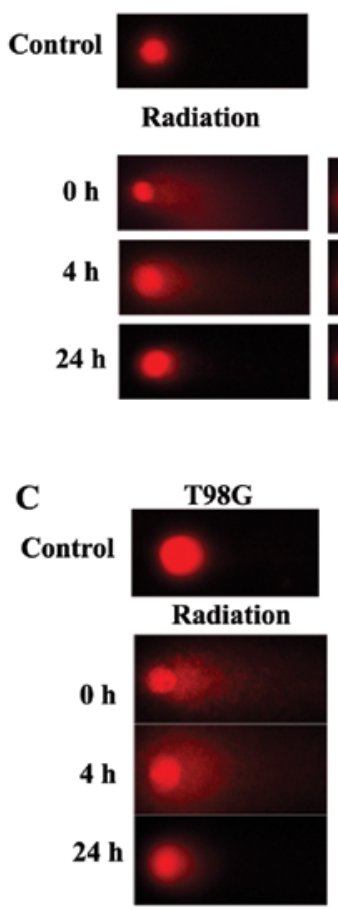

Radiation with ELE

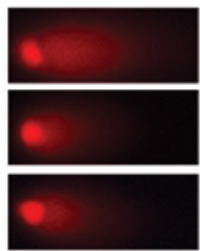

Radiation with ELE

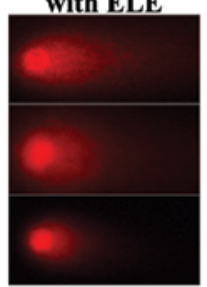

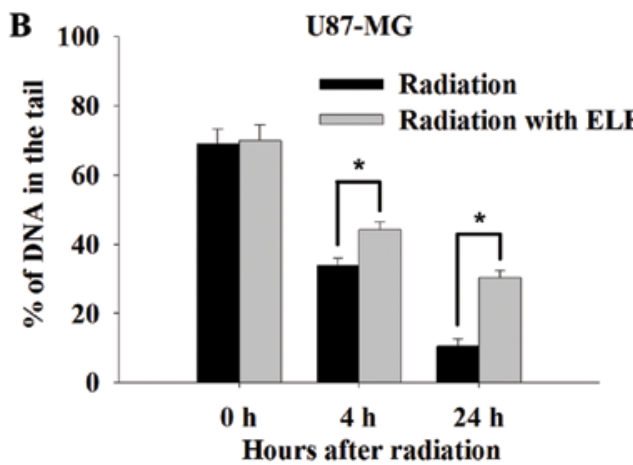

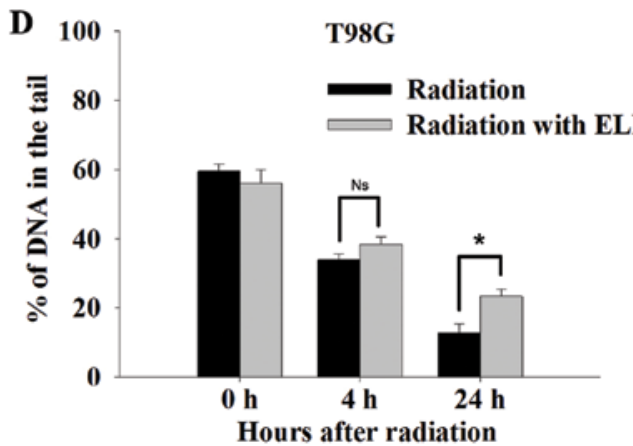

Figure 3. $\beta$-elemene enhances the radiation-induced DNA damage of GBM cells. Human GBM cell lines U87-MG (A and B) and T98G (C and D) were pretreated without or with $\beta$-elemene $(40 \mu \mathrm{g} / \mathrm{ml})$ for $24 \mathrm{~h}$, exposed to radiation at $4 \mathrm{~Gy}$ and collected for comet assay as described in Materials and methods. The percentage of DNA in the tail was calculated for 50 random cells. The results are expressed as the mean \pm SEM of at least three independent experiments. ${ }^{*} \mathrm{P}<0.05$, group treated with $\beta$-elemene vs. untreated group.
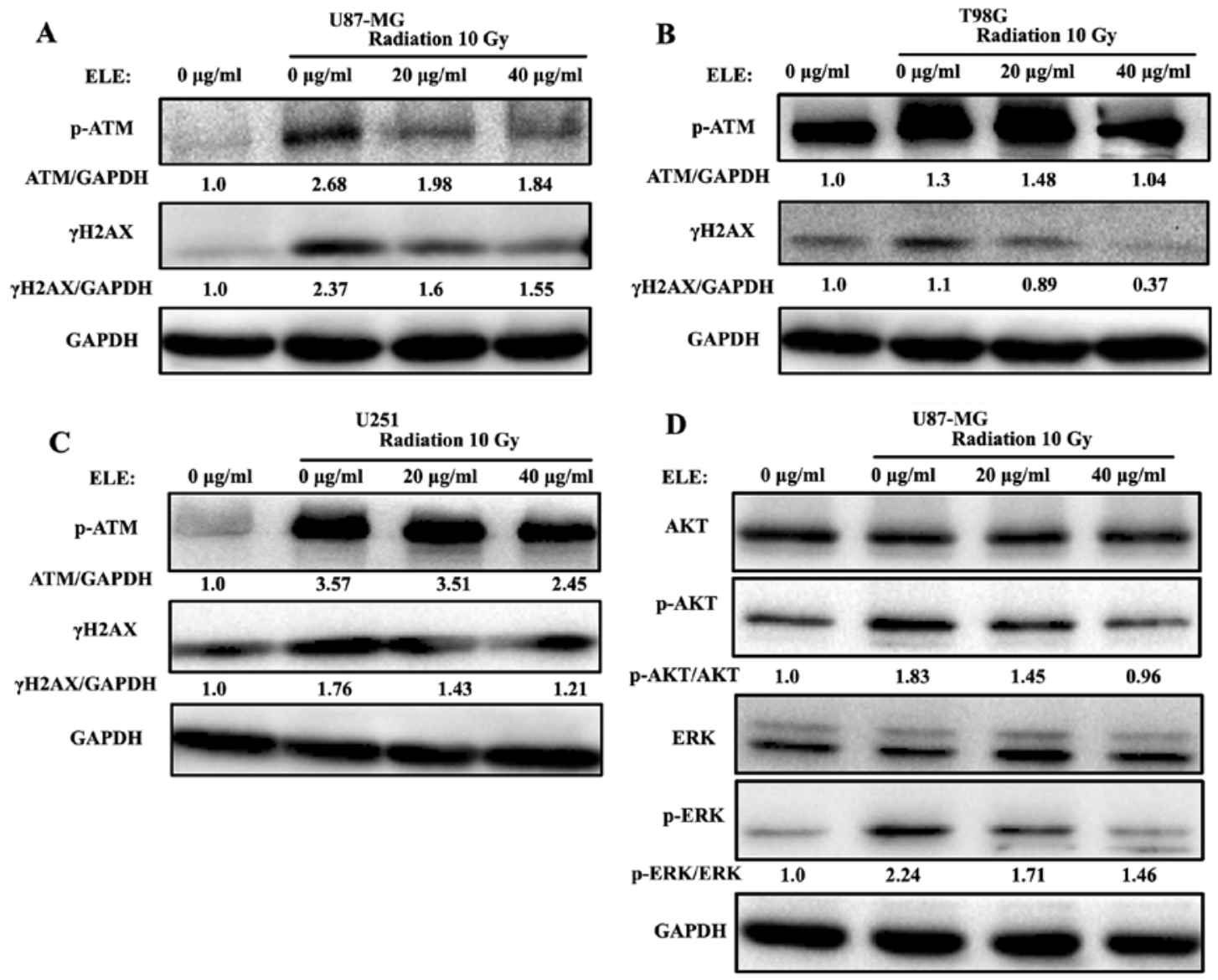

Figure 4. $\beta$-elemene inhibits the ATM, AKT and ERK signaling pathway in GBM cells when combined with radiation. Human GBM U87-MG, T98G and U251 cells were pretreated without or with $\beta$-elemene $(20$ and $40 \mu \mathrm{g} / \mathrm{ml})$ for $24 \mathrm{~h}$, exposed to radiation at $10 \mathrm{~Gy}$ and collected for immunoblotting after 5 min as described in Materials and methods. The levels of p-ATM, $\gamma \mathrm{H} 2 \mathrm{AX}(\mathrm{A}-\mathrm{C})$ and AKT, p-AKT, ERK and p-ERK (D) were evaluated. 

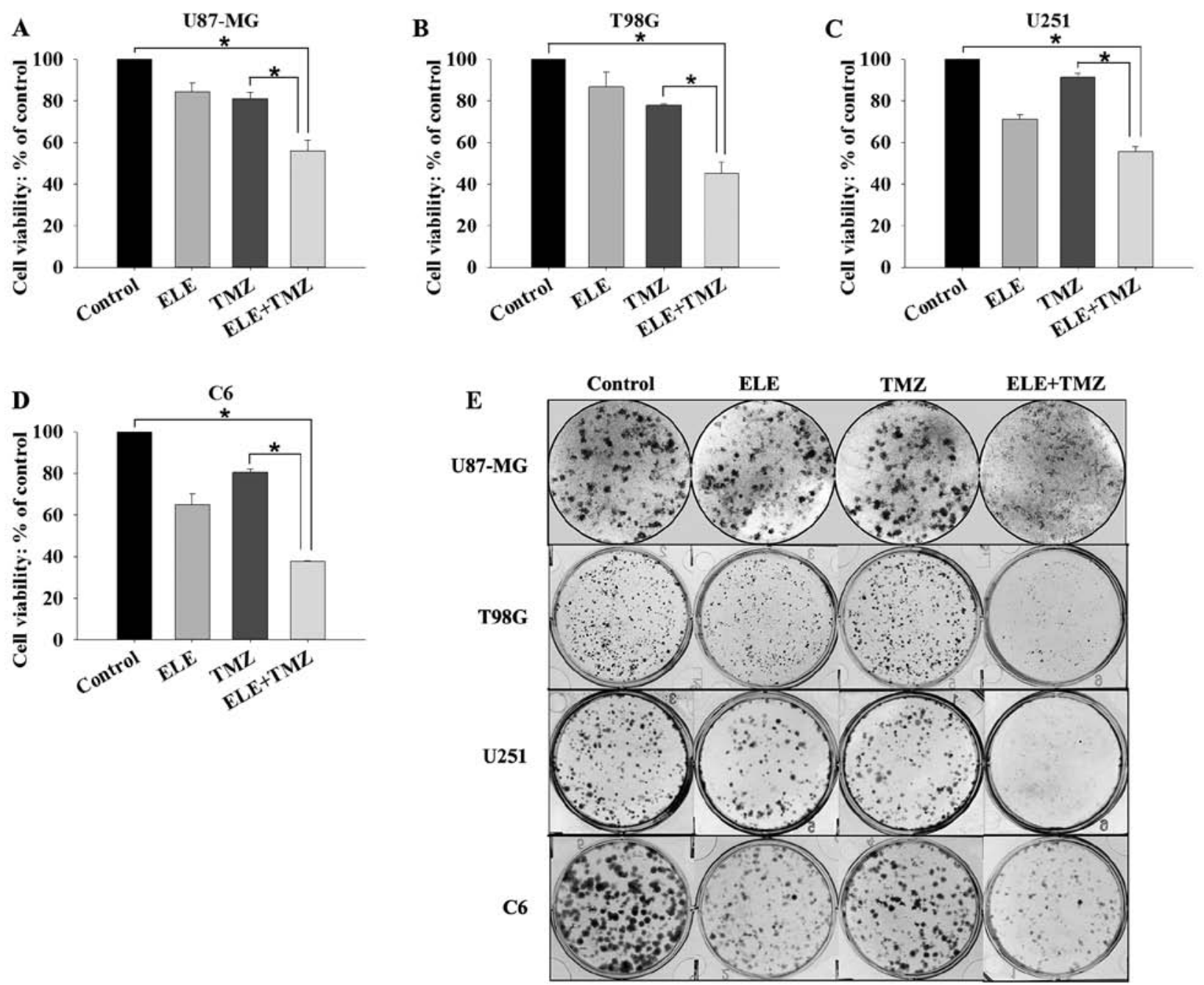

Figure 5. $\beta$-elemene increases the inhibitory effect of TMZ on proliferation of GBM cells. Human GBM U87-MG, T98G, U251 cells and rat GBM C6 cells were seeded in 96 -well plates at $5 \times 10^{3} /$ well and treated with $\beta$-elemene $(40 \mu \mathrm{g} / \mathrm{ml})$ alone, TMZ $(500 \mu \mathrm{M})$ alone or both for $48 \mathrm{~h}$. (A-D) The ability of $\beta$-elemene to increase the effect of TMZ was determined by MTT assays. (E) Colony formation for GBM cells. Cells were seeded in 6-well plates at 500/well and treated with $\beta$-elemene ( $30 \mu \mathrm{g} / \mathrm{ml})$ alone, TMZ (50 $\mu \mathrm{M}$ for U87-MG, U251 and C6; $100 \mu \mathrm{M}$ for T98G) alone or both for $48 \mathrm{~h}$. Then the medium was replaced with fresh medium and cultured for 14-20 days. The results are expressed as the mean \pm SEM of at least three independent experiments. ${ }^{*} \mathrm{P}<0.05$ vs. untreated control.

$\beta$-elemene increases the inhibitory effects of TMZ on the proliferation and survival of GBM cells. In order to determine the combinatorial effects of $\beta$-elemene and TMZ in GBM, we used MTT and colony formation assays to examine the effects of $\beta$-elemene plus TMZ in GBM cell lines U87-MG, T98G, U251 and C6 cells. T98G has been reported to be resistant to TMZ (11). We examined the different effects of TMZ at 0, 100, 250,500 and $1,000 \mu \mathrm{M}$ on GBM cells for $48 \mathrm{~h}$ by MTT assay and selected $500 \mu \mathrm{M}$ for the following combination experiments. We treated the cells with $\beta$-elemene alone $(40 \mu \mathrm{g} / \mathrm{ml})$, TMZ alone $(500 \mu \mathrm{M})$ or both for $48 \mathrm{~h}$, and then examined the effects using the MTT assay (Fig. 5A-D). We found that $\beta$-elemene markedly increased the TMZ-induced inhibition of cell proliferation in the four cell lines and the CI was calculated: 0.87 for U87-MG, 0.672 for T98G, 0.857 for U251, 0.699 for C6 cells. For the colony formation assay (Fig. 5E), the cells were seeded in 6-well plate for $24 \mathrm{~h}$ at 500/well, and treated with the indicated concentrations of $\beta$-elemene alone, TMZ alone or the combination for $48 \mathrm{~h}$, and then cultured for 14-20 days. The numbers of the colonies were fewer and the sizes were smaller in the combination treatment group when compared to the group treated with TMZ alone or the control. The data demonstrated that $\beta$-elemene strongly enhanced the inhibition of cell proliferation and survival induced by TMZ in the human and rat GBM cell lines and it was more effective in the TMZ-resistant cell line T98G.

\section{$\beta$-elemene inhibits TMZ-induced activation of ATM, AKT and} ERK signaling and enhances DNA damage of TMZ. We used the comet assay to examine the DNA damage of GBM cells treated with $\beta$-elemene and TMZ, and assessed the change in the p-ATM and total/phosphorylated levels of AKT and ERK proteins by immunoblotting at the same time. The human GBM cell line T98G was treated with $\beta$-elemene alone $(40 \mu \mathrm{g} /$ $\mathrm{ml})$, TMZ alone $(500 \mu \mathrm{M})$ or both for $48 \mathrm{~h}$ and collected for comet assay and immunoblotting. The percentage of DNA in the tail was almost $50 \%$ in the combined group and was higher than that in the group treated with TMZ alone. We also found that TMZ enhanced the phosphorylation of ATM, AKT and ERK, whereas $\beta$-elemene reduced their phosphorylated 
A

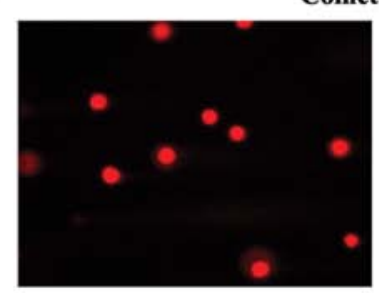

Control

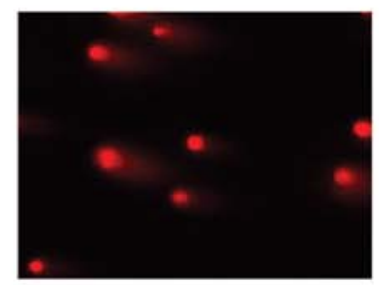

TMZ
Comet assay

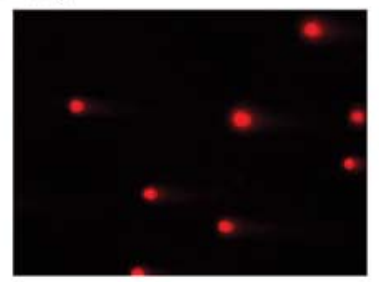

ELE

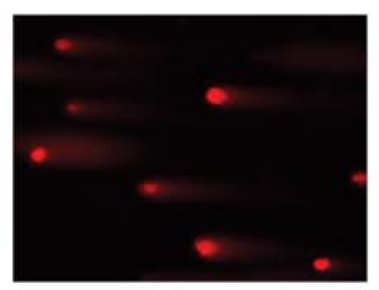

ELE+TMZ

B

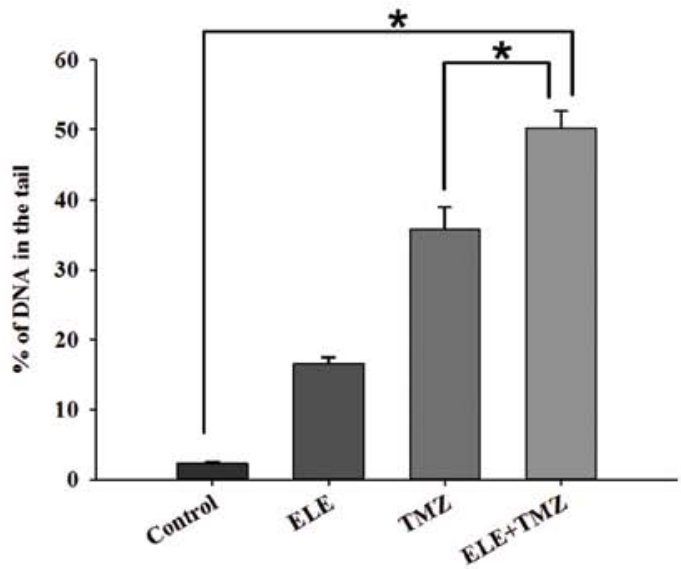

C

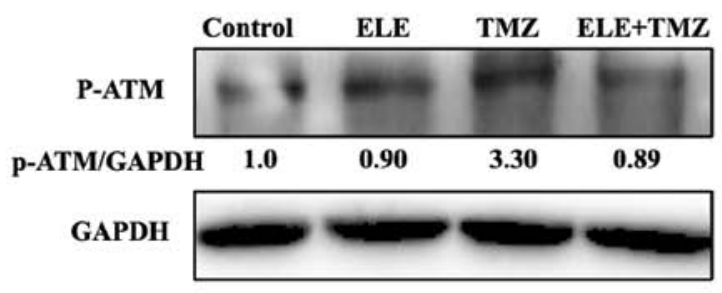

D

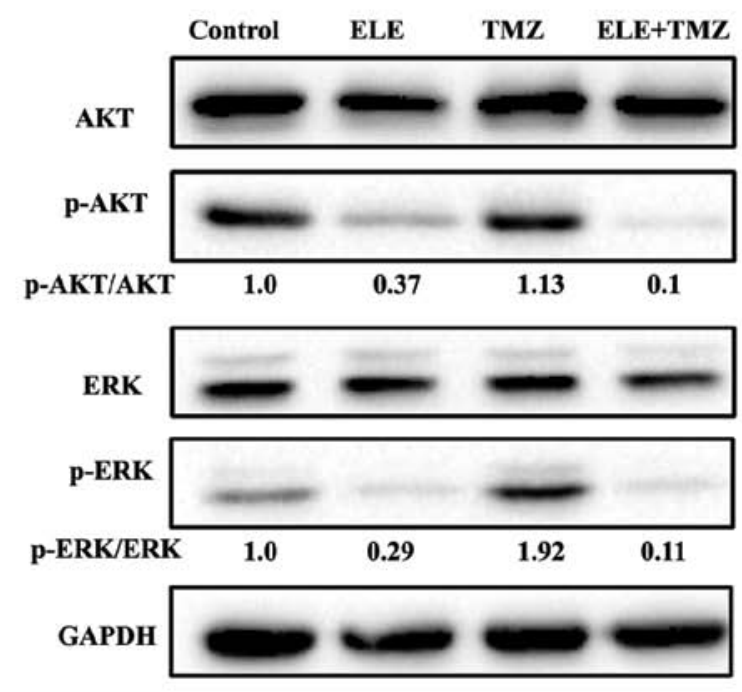

Figure 6. $\beta$-elemene inhibits the phosphorylation of ATM, AKT and ERK to enhance the DNA damage of GBM cells combined with TMZ. Human GBM T98G cells were treated with $\beta$-elemene $(40 \mu \mathrm{g} / \mathrm{ml})$ alone, TMZ $(500 \mu \mathrm{M})$ alone or both for $48 \mathrm{~h}$ and then collected for (A and B) comet assay or (C and D) immunoblotting. The levels of p-ATM (C) and AKT, p-AKT, ERK, p-ERK (D) were evaluated. The results are expressed as the mean \pm SEM of at least three independent experiments. ${ }^{*} \mathrm{P}<0.05$, group treated with $\beta$-elemene vs. untreated group.

counterparts compared to the total protein levels which were not affected in T98G cells (Fig. 6). Thus, $\beta$-elemene decreased the phosphorylation of ATM, AKT and ERK and inhibited the DNA damage repair caused by TMZ.

\section{Discussion}

The resistance to radiotherapy and chemotherapy of glioblastoma multiforme is a critical issue associated with its poor prognosis and reduced patient survival. New treatments to reverse the resistance are urgently needed. $\beta$-elemene, a Chinese medicine, has demonstrated antitumor effects in many types of tumors (13-17) with low toxicity, and has been widely used in China. Some reports have shown that $\beta$-elemene has a sensitization effect on radiotherapy and cisplatin in lung cancer cells $(19,20)$. We carried out clinical experiments of $\beta$-elemene on patients with GBM. We found that injection of $\beta$-elemene through the internal carotid artery had significant effects on reducing the size of tumors. The antitumor effect of $\beta$-elemene on GBM patients is definite, and $\beta$-elemene has few side-effects with some local vasculitis (21). It has been reported that $\beta$-elemene increased the ratio of Bax:Bcl-2, and activated caspase- $-9,-3$ and -7 to induce the apoptosis of GBM cells $(22,23)$. $\beta$-elemene can also activate the p38 MAPK (17) and inactivate RAF/MEK/ ERK signaling pathways to induce cell cycle arrest of GBM cells in the G0/G1 phase (23).

We found that $\beta$-elemene inhibited the proliferation of GMB cell lines and had a sensitization effect on radiotherapy. Our data showed that $\beta$-elemene co-treated with radiation increased the inhibition of DNA damage repair.

The ataxia telangiectasia mutated (ATM) kinase is triggered by DSB formation and initiates a series of signaling events by phosphorylating substrate proteins (8). ATM is a 350-kDa protein that exists as an inactive dimer and undergoes monomerization following DSB induction. Phosphorylated ATM regulates cell cycle checkpoints through p53 phosphorylation at Ser15 and activates checkpoint kinase 2 (CHK2) through phosphorylation at Thr68 $(24,25)$. As ATM kinase is a potential therapeutic target for the therapy of GBM, the ATM inhibitor increases the death of GBM cells combined with radiation $(9,26,27)$. Histone $\mathrm{H} 2 \mathrm{AX}$ can be phosphorylated by p-ATM to $\gamma \mathrm{H} 2 \mathrm{AX}$ and takes parts in the repair of DNA damage directly, thus, we not only tested the level of p-ATM but also $\gamma \mathrm{H} 2 \mathrm{AX}$ to measure the DNA damage repair after radiotherapy. 
In the present study, we showed that $\beta$-elemene inhibited the phosphorylation of ATM after radiation. The levels of p-ATM decreased depending on the concentrations of $\beta$-elemene. The downstream protein, $\gamma \mathrm{H} 2 \mathrm{AX}$ was also decreased by $\beta$-elemene. We also found that untreated T98G cells had a higher level of p-ATM, and this may be the reason why $\mathrm{T} 98 \mathrm{G}$ is more resistant to radiotherapy. Thus, $\beta$-elemene enhances the sensitivity of GBM cells to radiation via inhibiting the activation of the ATM signaling pathway to reduce DNA damage repair.

The constitutive activation of AKT and ERK in GBM cells increases the ability of survival, proliferation, migration and invasion (10). The radiosensitivity of GBM cells can be affected by AKT and ERK signaling pathways through promoting the activation of the catalytic subunit of DNA-dependent protein kinase (DNA-PKcs) (28). ERK and AKT signaling pathways have positive effects on DSB repair in an ATM-dependent manner (29). It has been discovered that ATM indirectly induces AKT and ERK phosphorylation, and inhibiting the ATM kinase with an ATM-specific inhibitor was found to reduce the phosphorylation of AKT and ERK (30,31). Meanwhile, the phosphorylated ERK promotes ATM-dependent foci formation, making ATM and ERK signaling under the control of a regulatory feedback loop (32). Our findings showed that the total AKT and ERK did not change significantly after treatment while the phosphorylation of AKT and ERK was inhibited by $\beta$-elemene with increased concentrations.

As TMZ is the first-line alkylating agent in clinical therapy and has an antitumor effect by inducing DNA damage, we examined the effect of $\beta$-elemene combined with TMZ and found that $\beta$-elemene had a chemosensitizing effect on TMZ. The phosphorylation of ATM, AKT and ERK induced by TMZ were reduced by $\beta$-elemene to inhibit the repair of DNA damage. In addition, the effect on the TMZ-resistant cell line T98G was more pronounced following the combination of $\beta$-elemene and TMZ which indicated that $\beta$-elemene could reverse the resistance of GBM cells to TMZ.

The present study demonstrated that $\beta$-elemene not only inhibited the proliferation but also enhanced the radiosensitivity and chemosensitivity of GBM cells. We found that $\beta$-elemene inhibited the DNA damage repair induced by both radiation and TMZ by decreasing the levels of phosphorylated ATM, AKT and ERK. Thus, $\beta$-elemene may be used as a potential novel drug in combination with the radiotherapy and chemotherapy of GBM.

\section{Acknowledgements}

The present study was supported by funds from the National Science Foundation of China (no. 81202964), the Liaoning Province Natural Science Foundation of China (no. 2013023043). Y.Z. and Y.Y. received the funding.

\section{References}

1. Louis DN, Ohgaki H, Wiestler OD, Cavenee WK, Burger PC, Jouvet A, Scheithauer BW and Kleihues P: The 2007 WHO classification of tumours of the central nervous system. Acta Neuropathol 114: 97-109, 2007.
2. Preusser M, de Ribaupierre S, Wöhrer A, Erridge SC, Hegi M, Weller M and Stupp R: Current concepts and management of glioblastoma. Ann Neurol 70: 9-21, 2011.

3. Wilson TA, Karajannis MA and Harter DH: Glioblastoma multiforme: State of the art and future therapeutics. Surg Neurol Int 5: 64, 2014.

4. Ostrom QT, Gittleman H, Farah P, Ondracek A, Chen Y, Wolinsky Y, Stroup NE, Kruchko C and Barnholtz-Sloan JS: CBTRUS statistical report: Primary brain and central nervous system tumors diagnosed in the United States in 2006-2010. Neuro Oncol 15 (Suppl 2): ii1-ii56, 2013.

5. Bai RY, Staedtke V and Riggins GJ: Molecular targeting of glioblastoma: Drug discovery and therapies. Trends Mol Med 17: 301-312, 2011.

6. Jiang G, Li LT, Xin Y, Zhang L, Liu YQ and Zheng JN: Strategies to improve the killing of tumors using temozolomide: Targeting the DNA repair protein MGMT. Curr Med Chem 19: 3886-3892, 2012.

7. Bei R, Marzocchella L and Turriziani M: The use of temozolomide for the treatment of malignant tumors: Clinical evidence and molecular mechanisms of action. Recent Patents Anticancer Drug Discov 5: 172-187, 2010.

8. Begg AC, Stewart FA and Vens C: Strategies to improve radiotherapy with targeted drugs. Nat Rev Cancer 11: 239-253, 2011.

9. Eich M, Roos WP, Nikolova T and Kaina B: Contribution of ATM and ATR to the resistance of glioblastoma and malignant melanoma cells to the methylating anticancer drug temozolomide. Mol Cancer Ther 12: 2529-2540, 2013.

10. Nathanson DA, Gini B, Mottahedeh J, Visnyei K, Koga T, Gomez G, Eskin A, Hwang K, Wang J, Masui K, et al: Targeted therapy resistance mediated by dynamic regulation of extrachromosomal mutant EGFR DNA. Science 343: 72-76, 2014.

11. Vlachostergios PJ, Hatzidaki E, Befani CD, Liakos P and Papandreou CN: Bortezomib overcomes MGMT-related resistance of glioblastoma cell lines to temozolomide in a schedule-dependent manner. Invest New Drugs 31: 1169-1181, 2013.

12. Williams TM, Flecha AR, Keller P, Ram A, Karnak D, Galbán S, Galbán CJ, Ross BD, Lawrence TS, Rehemtulla A, et al: Cotargeting MAPK and PI3K signaling with concurrent radiotherapy as a strategy for the treatment of pancreatic cancer. Mol Cancer Ther 11: 1193-1202, 2012.

13. Wang G, Li X, Huang F, Zhao J, Ding H, Cunningham C, Coad JE, Flynn DC, Reed E and Li QQ: Antitumor effect of beta-elemene in non-small-cell lung cancer cells is mediated via induction of cell cycle arrest and apoptotic cell death. Cell Mol Life Sci 62: 881-893, 2005.

14. Li QQ, Wang G, Liang H, Li JM, Huang F, Agarwal PK, Zhong Y and Reed E: $\beta$-Elemene promotes cisplatin-induced cell death in human bladder cancer and other carcinomas. Anticancer Res 33: 1421-1428, 2013.

15. Yu Z, Wang R, Xu L, Xie S, Dong J and Jing Y: $\beta$-Elemene piperazine derivatives induce apoptosis in human leukemia cells through downregulation of c-FLIP and generation of ROS. PLoS One 6: e15843, 2011

16. Li QQ, Lee RX, Liang H, Wang G, Li JM, Zhong Y and Reed E: $\beta$-elemene enhances susceptibility to cisplatin in resistant ovarian carcinoma cells via downregulation of ERCC-1 and XIAP and inactivation of JNK. Int J Oncol 43: 721-728, 2013.

17. Yao YQ, Ding X, Jia YC, Huang CX, Wang YZ and Xu YH: Anti-tumor effect of beta-elemene in glioblastoma cells depends on p38 MAPK activation. Cancer Lett 264: 127-134, 2008.

18. Fischel JL, Formento P and Milano G: Epidermal growth factor receptor double targeting by a tyrosine kinase inhibitor (Iressa) and a monoclonal antibody (Cetuximab). Impact on cell growth and molecular factors. Br J Cancer 92: 1063-1068, 2005.

19. Li QQ, Wang G, Huang F, Li JM, Cuff CF and Reed E: Sensitization of lung cancer cells to cisplatin by $\beta$-elemene is mediated through blockade of cell cycle progression: Antitumor efficacies of $\beta$-elemene and its synthetic analogs. Med Oncol 30: $488,2013$.

20. Zou K, Tong E, Xu Y, Deng X and Zou L: Down regulation of mammalian target of rapamycin decreases HIF-lalpha and survivin expression in anoxic lung adenocarcinoma A549 cell to elemene and/or irradiation. Tumour Biol 35: 9735-9741, 2014.

21. Zhou HY, Xu YH and Luo QZ: The clinical studies of $\beta$-elemene's anti-tumor effect on gliomas. J Med J Liaoning 17: 189-191, 2003. 
22. Zhang H, Xu F, Xie T, Jin H and Shi L: $\beta$-elemene induces glioma cell apoptosis by downregulating survivin and its interaction with hepatitis B X-interacting protein. Oncol Rep 28: 2083-2090, 2012.

23. Zhao YS, Zhu TZ, Chen YW, Yao YQ, Wu CM, Wei ZQ, Wang $\mathrm{W}$ and Xu YH: B-elemene inhibits Hsp90/Raf-1 molecular complex inducing apoptosis of glioblastoma cells. J Neurooncol 107: 307-314, 2012.

24. Barlow C, Brown KD, Deng CX, Tagle DA and WynshawBoris A: Atm selectively regulates distinct p53-dependent cell-cycle checkpoint and apoptotic pathways. Nat Genet 17: 453-456, 1997.

25. Matsuoka S, Rotman G, Ogawa A, Shiloh Y, Tamai K and Elledge SJ: Ataxia telangiectasia-mutated phosphorylates Chk2 in vivo and in vitro. Proc Natl Acad Sci USA 97: 10389-10394, 2000.

26. Biddlestone-Thorpe L, Sajjad M, Rosenberg E, Beckta JM, Valerie NC, Tokarz M, Adams BR, Wagner AF, Khalil A, Gilfor D, et al: ATM kinase inhibition preferentially sensitizes p53-mutant glioma to ionizing radiation. Clin Cancer Res 19: 3189-3200, 2013.

27. Golding SE, Rosenberg E, Adams BR, Wignarajah S, Beckta JM, O'Connor MJ and Valerie K: Dynamic inhibition of ATM kinase provides a strategy for glioblastoma multiforme radiosensitization and growth control. Cell Cycle 11: 1167-1173, 2012.
28. Mukherjee B, McEllin B, Camacho CV, Tomimatsu N, Sirasanagandala S, Nannepaga S, Hatanpaa KJ, Mickey B, Madden C, Maher E, et al: EGFRvIII and DNA double-strand break repair: A molecular mechanism for radioresistance in glioblastoma. Cancer Res 69: 4252-4259, 2009.

29. Khalil A, Morgan RN, Adams BR, Golding SE, Dever SM, Rosenberg E, Povirk LF and Valerie K: ATM-dependent ERK signaling via AKT in response to DNA double-strand breaks. Cell Cycle 10: 481-491, 2011.

30. Viniegra JG, Martínez N, Modirassari P, Hernández Losa J, Parada Cobo C, Sánchez-Arévalo Lobo VJ, Aceves Luquero CI, Alvarez-Vallina L, Ramón y Cajal S, Rojas JM, et al: Full activation of $\mathrm{PKB} / \mathrm{Akt}$ in response to insulin or ionizing radiation is mediated through ATM. J Biol Chem 280: 4029-4036, 2005.

31. Golding SE, Rosenberg E, Neill S, Dent P, Povirk LF and Valerie K: Extracellular signal-related kinase positively regulates ataxia telangiectasia mutated, homologous recombination repair, and the DNA damage response. Cancer Res 67: 1046-1053, 2007.

32. Munshi A and Ramesh R: Mitogen-activated protein kinases and their role in radiation response. Genes Cancer 4: 401-408, 2013. 